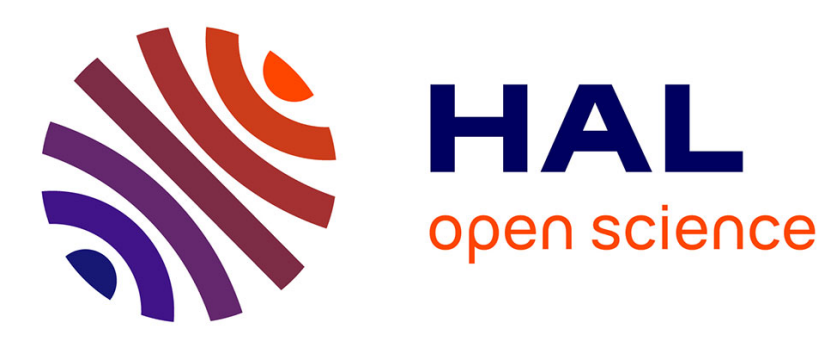

\title{
Vibrational dynamics and structural relaxation in aqueous electrolyte solutions in the liquid, undercooled liquid and glassy states
}

J. Dupuy, J. Jal, B. Prével, A. Aouizerat-Elarby, P. Chieux, A. J. Dianoux, J. Legrand

\section{To cite this version:}

J. Dupuy, J. Jal, B. Prével, A. Aouizerat-Elarby, P. Chieux, et al.. Vibrational dynamics and structural relaxation in aqueous electrolyte solutions in the liquid, undercooled liquid and glassy states. Journal de Physique IV Proceedings, 1992, 02 (C2), pp.C2-179-C2-184. 10.1051/jp4:1992225 . jpa-00251296

\section{HAL Id: jpa-00251296 https://hal.science/jpa-00251296}

Submitted on 1 Jan 1992

HAL is a multi-disciplinary open access archive for the deposit and dissemination of scientific research documents, whether they are published or not. The documents may come from teaching and research institutions in France or abroad, or from public or private research centers.
L'archive ouverte pluridisciplinaire HAL, est destinée au dépôt et à la diffusion de documents scientifiques de niveau recherche, publiés ou non, émanant des établissements d'enseignement et de recherche français ou étrangers, des laboratoires publics ou privés. 


\title{
Vibrational dynamics and structural relaxation in aqueous electrolyte solutions in the liquid, undercooled liquid and glassy states
}

\author{
J. DUPUY, J. F. JAL, B. PRÉVEL, A. AOUIZERAT-ELARBY, P. CHIEUX*, A. J. DIANOUX* \\ and J. F. LEGRAND*
}

Département de Physique des Matériaux, UA. 172, Université Claude Bernard Lyon I, 43 bd du 11 novembre 1918, 69622 Villeurbanne Cedex, France

${ }^{*}$ Institut Laue Langevin, BP. 156 X, 38042 Grenoble Cedex, France

\section{Summary}

In very concentrated aqueous electrolyte solutions, the competition between dipolar and ionic forces and most of the system properties, are finely monitored by the concentration. For $\mathrm{LiCl}$, $\mathrm{RH}_{2} \mathrm{O}$ ( $\mathrm{R}$ being the number of water moles per mole of salt) two domains of concentration exist around even hydration numbers $R=6$ and $R=4$, which can be reversibly undercooled from the liquid to the glassy state. At other concentrations, for $\mathrm{R}<12$, metastability is achieved only in a restricted temperature range.

The collective behaviour as well as individual atomic motions, have been studied by neutron inelastic scattering in the.metastable state of $\mathrm{LiCl}, 6 \mathrm{H}_{2} \mathrm{O}$ and $\mathrm{LiCl}, 4 \mathrm{H}_{2} \mathrm{O}$ down to the glass transition.

The study of the structural relaxation by neutron spin echo (NSE) allows us to show that the temperature dependence of the response of the system follows a scaling relation with a cross-over at a phase transition present in the liquid phase.

Increasing hydrodynamic interactions in a liquid is certainly the best manner to analyse the intrinsic and microscopic correlations into the system. So the various motions, collective, relaxational, individual and their coupling can be revealed by approaching glass formation conditions.

$\mathrm{LiCl}, \mathrm{RH}_{2} \mathrm{O}$ (or $\mathrm{LiCl}, \mathrm{RD}_{2} \mathrm{O}$ ) is one of the most suitable system because by changing $\mathbf{R}$ (the number of water molecules per molecule of salt) we change strongly the nature of the medium and by using isotopic substitution on $\mathrm{Li}^{+}, \mathrm{Cl}^{-}, \mathrm{D}$ we can differentiate the dynamics of the various atoms or ions.

Changing $R$ gives the possibility to analyse two types of liquids : the first one, for $R>6$ is intrinsically inhomogeneous, and described by a regular mixture of pure water and the hydrate $\mathrm{LiCl}, 6 \mathrm{H}_{2} \mathrm{O}(1)$. The second one, for $\mathrm{R}<6$ is a mixture in which the competitions between dipolar forces and coulombic forces are finely monitored.

In this paper, we summarize some recent analysis of different kinds of dynamical responses which lead to some questions on their non linear behaviour. 
The total dynamical responses of the electrolyte $\mathrm{LiCl}, 6 \mathrm{H}_{2} \mathrm{O}$ and $\mathrm{LiCl}, 4 \mathrm{H}_{2} \mathrm{O}$ have been analyzed between $0.3 \mathrm{meV}$ and $120 \mathrm{meV}$, i.e. in a domain of frequencies covering collective vibrational response and individual motion of ions.

\section{Dynamical structure factor.}

From the dynamical structure factor $S(q, \omega)$ measured with the IN 6 instrument (ILL, Grenoble) at a resolution of $80 \mu \mathrm{eV}$, for $\mathrm{LiCl}, \mathrm{R} \mathrm{H}_{2} \mathrm{O}$ (with $\mathrm{R}=6$ ), two types of informations can be derived :

(i) - the frequency distribution $G(E) \quad(E=h \omega)$ (extracted as in ref (3), neglecting the incoherent contribution to the scattering), which permits an analysis of the characteristic frequencies (2)which define this low energy "vibrational network" (3).

(ii) - The central mode,i.e diffusive processes from the quasi elastic behaviour around $\mathrm{E}=0$.

A - In the frequency distribution, three fundamental modes of the $\mathrm{H}$-bonded network dominate : bending at $7 \mathrm{meV}$, restricted translational motion or stretching at $23 \mathrm{meV}$, and restricted rotational motion or libration at $85 \mathrm{meV}$ (see figure 1). The identification of these modes has been made by comparison with experiment on pure water (2) (10).

Fig. 1. Generalized density of states obtained for $\mathrm{LiCl}, 6 \mathrm{H}_{2} \mathrm{O}$ in the glassy and liquid states and assignements of the principal bands for the liquid state (see 2).

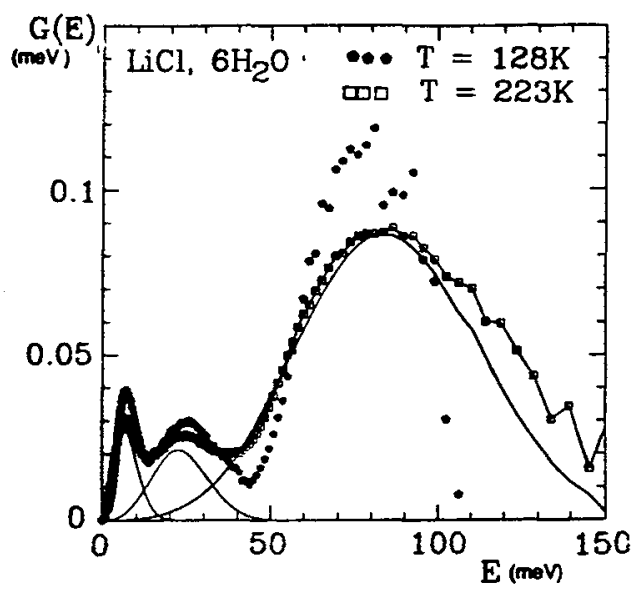

The influence of temperature on the different modes has been followed in this desordered systemdown to the non ergodic situation ( $\mathrm{T}<142 \mathrm{~K}$ for $\mathrm{LiCl}, 6 \mathrm{H}_{2} \mathrm{O}$ ). (Fig. 2)

BENDING

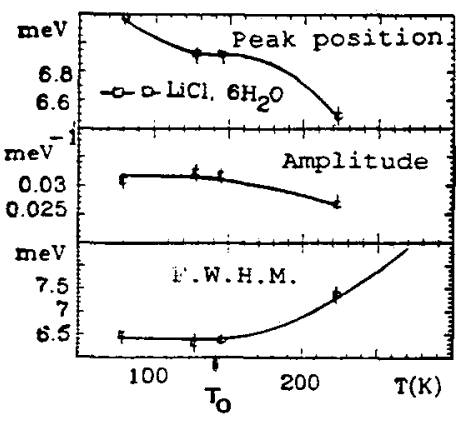

STRETCHING

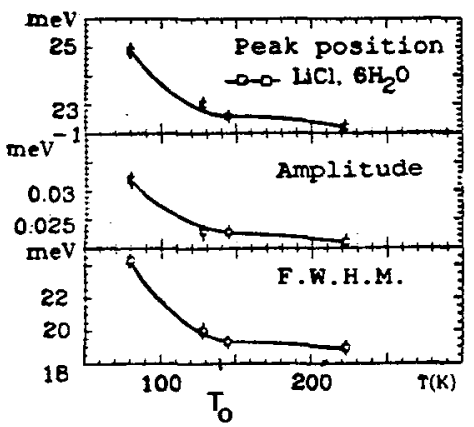

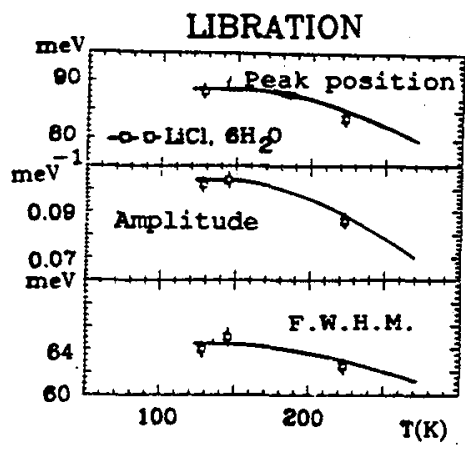

Fig 2. Evolution of the three fundamental bands characterizing the bending, stretching, librational motions assigned to $\mathrm{H}$ bonded $\mathrm{H}_{2} \mathrm{O}$ in $\mathrm{LiCl}, 6 \mathrm{H}_{2} \mathrm{O}$ versus temperature. 
- The broadening of the bending motion which is large in the liquid state is correlated to the existence of different microscopic dynamical configurations. This mode has a significant assymetry towards high energies which increases with temperature, giving some support to a delocalization of the excitations or a fluctuating coupling between different microscopic configurations (12)

- Among these modes, stretching is the most influenced by the glass transition or equivalently by To i.e the lowest temperature limit of liquid metastability(2) However the limited range of energy that we were able to reach, does not permit us to fully analyze the low temperature behaviour for librational modes. There is another temperature of interest which is characteristic of a third order phase transition in the liquid(quoted by $T_{p}=$ peritexy at $207 \mathrm{~K}$ ). It appears that the stretching mode is nearly temperature independant in the low temperature supercooled liquid for $\mathrm{T}_{\mathrm{o}}<\mathrm{T}<\mathrm{T}_{\mathrm{p}}$. This temperature range is characterized by additional microscopic configurations (hydration 5) compared to those of the room temperature liquid.

B - Quasi elastic data, i.e. the central mode, permits to obtain informations on the individual motion of $\mathrm{H}$ or $\mathrm{D}$ in $\mathrm{H}_{2} \mathrm{O}$ and $\mathrm{D}_{2} \mathrm{O}$. At the composition $\mathrm{R}=6$, the system is molecular and although there is no correct diffusion's analysis of the different elements $\mathrm{Li}^{+}, \mathrm{Cl}^{-}$and $\mathrm{H}_{2} \mathrm{O}$, the trends give $\mathrm{D}_{\mathrm{Li}^{+}}<\mathrm{D}_{\mathrm{Cl}^{-}}<\mathrm{D}_{2} \mathrm{O}$.at $25^{\circ} \mathrm{C}(4)$

- The proton delocalization due to vibrations is deduced from the Debye Waller component. It is obtained from the total quasielastic intensity, I and is shown in fig. 3a and fig. $3 \mathrm{~b}$ for $\mathrm{LiCl}, 6 \mathrm{H}_{2} \mathrm{O}$ and $\mathrm{LiCl}, 4 \mathrm{H}_{2} \mathrm{O}$.

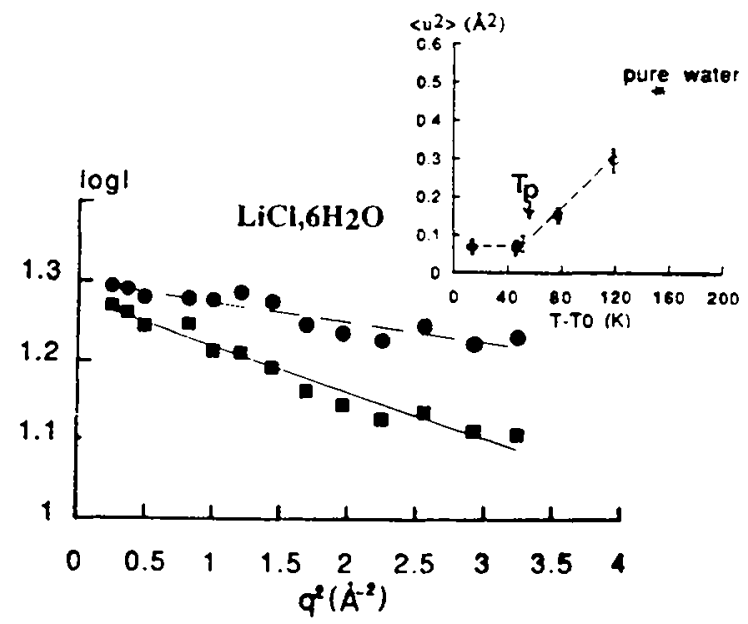

Fig. 3 a. Debye-Waller factor measured by QENS for $\mathrm{LiCl}, 6 \mathrm{H}_{2} \mathrm{O}$ in the liquid $(*) 223 \mathrm{~K}$ and in the super-cooled liquid : $(\bullet) 192 \mathrm{~K}$

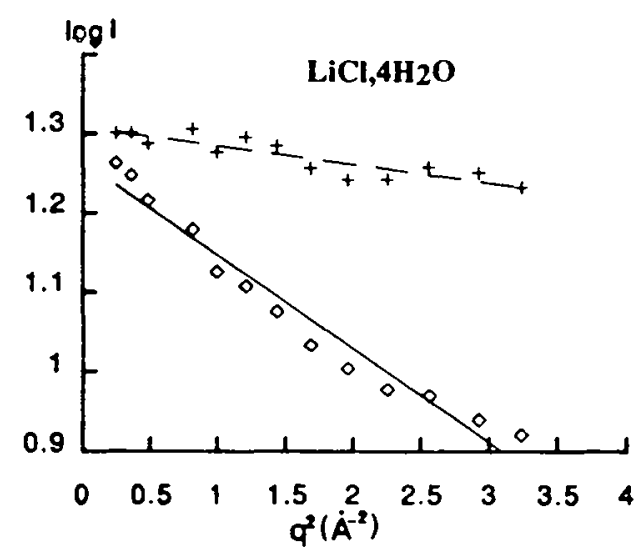

Fig. 3b. Debye-Waller factor measurcd by QENS for $\mathrm{LiCl}, 4 \mathrm{H}_{2} \mathrm{O}$ in the liquid state $(\diamond)$

$275 \mathrm{Kand}$ in the supercooled liquid state $(+) 210 \mathrm{~K}$

Insert : Mean square displacement of $\mathrm{H}_{2} \mathrm{O}$ in $\mathrm{LiCl}, 6 \mathrm{H}_{2} \mathrm{O}$ and in $\mathrm{LiCl}, 4 \mathrm{H}_{2} \mathrm{O}$ in liquid and super-cooled liquid versus ( $\mathrm{T}-\mathrm{To}$ ), To being the lowest temperature limit of the liquid metastability.

* Proton delocalization in purc water (11) 
The mean square displacement obtained for $\mathrm{H}_{2} \mathrm{O}$ in $\mathrm{LiCl}, 6 \mathrm{H}_{2} \mathrm{O}$ and $\mathrm{LiCl}, 4 \mathrm{H}_{2} \mathrm{O}$ and refeared to $\mathbf{T}_{\mathbf{0}}$, lowest temperature limit of the metastability (10) is temperature dependent in the liquid state and nearly temperature independent in the supercooled liquid.

This effect is induced by a restricted translational motion due to interactions of $\mathrm{H}_{2} \mathrm{O}$ with $\mathrm{Li}^{+}$and $\mathrm{Cl}^{-}$

- The diffusion coefficient of $\mathrm{H}_{2} \mathrm{O}$ can be obtained from $S(q, \omega)$ and compared to the ordinary diffusion law (5). As a matter of fact, the diffusion can be coupled to the hydrodynamics of the medium, the coupling being function of the kinematic viscosity $D_{\mathrm{T}}$, according to $\delta=\mathrm{D} /(\mathrm{D}+$ $\left.\mathrm{D}_{\mathrm{T}}\right)(5)$. The $\mathrm{q}$ dependence of the half width of the central mode given in fig. 4 for $\mathrm{LiCl}, 6 \mathrm{H}_{2} \mathrm{O}$ permits to obtain diffusion coefficient in agreement with litterature (4).

$\Delta \mathrm{E} / \mathrm{q}^{2}\left(\mathrm{meV} \AA^{2}\right)$

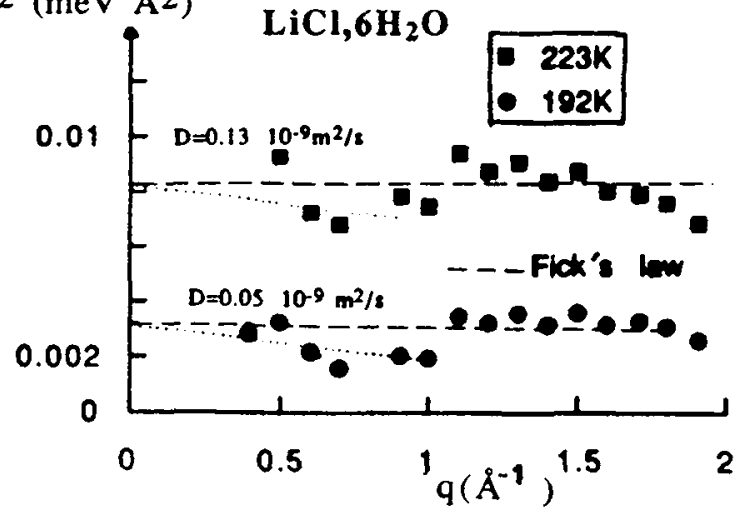

The narrowing of the central mode for all $q$ values inferior to $q_{\max }\left(\approx 1.9 \AA^{-1}\right)$ confirms the coupling of this mode with hydrodynamics (6).

Fig. 4. FWHM of $S(q, \omega)$ divided by $q^{2}$ for $\mathrm{LiCl}, 6 \mathrm{H}_{2} \mathrm{O}$ at different temperatures above and below $\mathrm{T}_{\mathrm{p}}$.

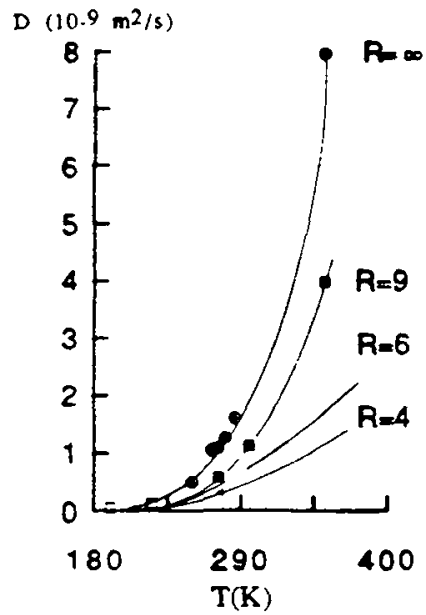

- The $\mathrm{H}_{2} \mathrm{O}$ diffusion coefficient obtained in this molecular system, for $R=6$ and $R=4$ permits to confirm the strong influence of the solvation on the dynamics of $\mathrm{H}_{2} \mathrm{O}$ when $\mathrm{R} \leq 6$ (fig 5)

Fig. 5. $\mathrm{H}_{2} \mathrm{O}$ diffusion coefficient evolution with temperature in $\mathrm{LiCl}, \mathrm{RH}_{2} \mathrm{O}$ for various $\mathrm{R}$. 


\section{Relaxational behaviour.}

The relaxational behaviour has been obtained on an "adequate" range of time $\left(10^{-12}\right.$ sec. to $\left.10^{-9} \mathrm{sec}\right)$ by NSE experiment performed on $\mathrm{IN} 11$ at $\mathrm{ML}(9)$ on $\mathrm{LiCl}, 6 \mathrm{D}_{2} \mathrm{O}$ at $\mathrm{q}=\mathrm{q}_{\max }=1.9 \AA^{-1}$, $\mathrm{q}_{\max }$ beeingthe momentum transfer of the main peak of the strcture factor at room temperature.

We deduce from this data (7), the evolution of the characteristic relaxational time $\tau_{\text {NSE }}$ which can be compared to the one obtained from viscosity (8) (fig. 6). Two scaling laws (10) give the evolution of $\tau$, with two characteristic temperatures of the system : lowest limit of the metastability $\mathrm{T}_{\mathrm{O}}$ and crystallisation temperature for the first hydrate formed $: \mathrm{R}=5$
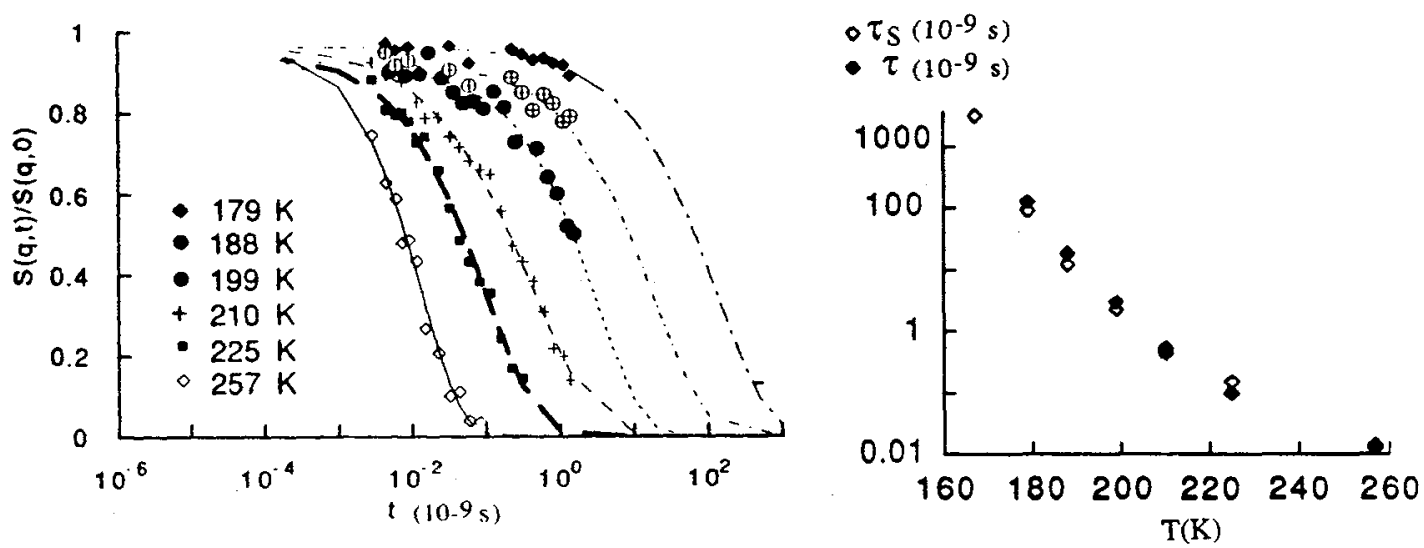

Fig. 6a. Neutron spin echo response at $\mathrm{q}=\mathrm{q}_{\max }=1,9 \AA$ for $\mathrm{LiCl}, 6 \mathrm{D}_{2} \mathrm{O}$ measured and analyzed according to ref. (7).

Fig 6b. Relaxational time deduced from NSE $(\bullet)$ for $\mathrm{LiCl}, 6 \mathrm{D}_{2} \mathrm{O}$ compared to $\tau_{\mathrm{S}}$ obtained from kinematic viscosity $(\diamond)$ according to ref. (8) for $\mathrm{LiCl}, 5.75 \mathrm{H}_{2} \mathrm{O}$.

This result confirms the connexion between the relaxational process and the third order phase transition, at $T_{p}$. Slowing down is observed in the supercooled liquid scaled to the lowest limit $T_{O}$ of the metastability.and the non ergodic character appears down to $\mathrm{T}_{\mathrm{O}}(7)$.

In conclusion, in these molecular aqueous solutions, collective vibrational motion of $\mathrm{H}_{2} \mathrm{O}$ such as stretching, mean square displacement and relaxational response in the hydrodynamic regime and at finite momentum transfer are sensible to the approach of some characteristic temperatures of the system such as $\mathrm{T}_{\mathrm{O}}$ and $\mathrm{T}_{\mathrm{p}}$ an apparent third order transition in the vicinity of the equilibrium melting point The existence of diffusive motion confirms the coupling with the hydrodynamics. The extension of these studies to the more concentrated domain, offers the opportunity to study the coupling between ionic conduction and relaxational slowing down. 


\section{References :}

[1] FORNAZERO J., El HACHADI A, DUPUY J, Molecular Structure (1991) 250, 421 A. El HACHADI - Thesis Lyon July 1991

[2] DUPUY J., JAL J.F., CHIEUX P., DIANOUX A.J., J. Molecular Structure (1991) 250, 315.

[3] DIANOUX A.J., Phil. Mag. B.1989, 59, 17.

(4) MMLS R., V.M.M. LOBO in Self diffusion in electrolyte solutions, Physical Sciences data 36 (1989) Elsevier.

[5] BOON J.P. , YIP S., Molecular hydrodynamics, Mac-Graw-Hill Inc (1980) MORKEL C, GRONEMEYER C., Z. Phys. B. Condensed Matter, 72, 433 (1988)

[6] de SCHEPPER I.M, ERNST R.H, Physica 98 A (1979) 189

[7] PREVEL B,JAL J.F, LEGRAND J.F, CHIEUX P,DUPUY J, to be published in Euro phys..

[8] MOYNIHAN C.T, BALITACTAC N,BOONE L, LITOVITZ J.A, J of Chem. Phys, (1971), $55,3013$.

[9] MEZEI, F, ED.Neutron Spin Echo in lecture Note in Physics 128 Springer-Verlag BerlinHeidelberg New-York (1980)

[10] DUPUY J, JAL J.F., CARMONA P, AOUIZERAT-ELARBY A., CHIEUX P, in Relaxation Complex Systems and related topics Ed by I.A. Campbell, C. Giovannello, Plenum Press N.Y. (1990) p. 175.

[11] LILLEY T.H., in Water. A comprehensive treatise F. Franks Ed (1973) 3, 265.

[12] International symposium "hydrogen bond physics" Il Ciocco Italie septembre 1990.

"H-Bond characteristic in supercooled and vitreous aqueous solutions"

"Ice nucleation and growth in Electrolytes : role of ionic forces" 